\title{
Ignition of Kerosene Droplets by Focused Microwaves
}

\author{
Beatrice Fragge $^{\star 1}$, Jérôme Sokoloff ${ }^{2}$, Olivier Rouzaud ${ }^{1}$, Olivier Pascal ${ }^{2}$, Mikael Orain ${ }^{1}$ \\ ${ }^{1}$ ONERA/DMPE, Université de Toulouse, 31055 Toulouse, France \\ ${ }^{2}$ LAPLACE, CNRS, Université de Toulouse, Toulouse, France \\ ${ }^{*}$ Corresponding author email: Beatrice.fragge@onera.fr
}

\begin{abstract}
The high demand for an alternative ignition system for air breathing engines has motivated lot of innovative studies in the last decades. The present paper discusses the results of kerosene droplet ignition with a waveguide based resonant cavity. We show that with this kind of setup, the needed power (injected in the cavity) required to ignite kerosene droplets (with diameter $130 \mu \mathrm{m}$ ) is as low as $4.5 \mathrm{~W}$, depending on the gap size.
\end{abstract}

\section{Keywords}

Kerosene Ignition, Microwave Plasma, Droplet Stream.

\section{Introduction}

New environmental regulations on pollutant emissions from air breathing engines led to the design of more efficient combustors, which often leads to an operation at leaner fuel-air mixtures. Approaching the lower ignition limit can cause problems such as combustion instability and flame blowout. A crucial example is the in-flight extinction of helicopters and aircraft engines that requires a reliable altitude relight in these critical conditions $\left(-56^{\circ} \mathrm{C}\right.$ and 0.2 bar). While for now the ignition is realized with a conventional spark plug, there has been a constant research for a new, more reliable, high energy ignition system over the last five decades.

Apart from diesel engines, automotive and air breathing engines are using spark plugs to create a plasma and ignite a fuel / air mixture under various thermodynamic conditions. Nonetheless, in the aeronautic industry, it is anticipated that additional environmental regulations will force manufacturers to introduce innovative engine architectures with larger operability and reduced pollutant emissions. These future engines will require highperformance ignition systems (higher repetition rate, controlled energy deposit, etc.), which motivates research activities worldwide. The works on plasma ignition comprise a lot of different approaches, including the use of laser sources [1,2], Radio Frequency (RF) Discharge [3,4,5], Dielectric Barrier Discharge (DBD) [6,7], Nanosecond discharge [8,9], and the use of Microwaves (MW) [10-17]. In this paper we present the study of ignition with a microwave system.

Most of the microwave ignition systems mentioned in the literature use a non-equilibrium plasma [18] due to its advantages compared to the plasma in thermal equilibrium in traditional spark plugs. In a non-equilibrium plasma, the electron temperature is much higher than the temperature of the heavy particles. This leads to a high acceleration of the electrons which increases the creation of radicals and energy transfer.

In the literature, the first studies on ignition of inflammable gases using RF and MW date from the 1970s and 1980s [5,11-12]. These authors studied ignition in the context of a potential hazard of antennas emitting waves near offshore platforms. Due to its positive influence on combustion, the first studies, of a meanwhile long list, on plasma assisted combustion and ignition were conducted $[19,20]$.

In the automotive domain, one promising device has been intensively studied: The Quarter Wave Coaxial Cavity Resonator (QWCCR) [14-17]. With this device, consisting of a coaxial line short-circuited at one end and open at the other, it is possible to create a plasma in air for pressures of $1 \mathrm{bar}$ and higher. This plasma is created at the tip of the inner conductor. 
In the aeronautic domain there is one interesting study to mention [10], where a plasma plume and a surface discharge have been used for ignition experiments. They showed a successful ignition of a realistic turbojet combustor, fuelled with kerosene at the following conditions: $T_{\text {fuel }}$ $=300 \mathrm{~K}, \mathrm{~T}_{\text {air }}=280 \mathrm{~K}-570 \mathrm{~K}, \mathrm{P}_{\text {air }}=0.1 \mathrm{MPa}$ and the Mach number of air $\mathrm{M}_{\text {air }}=0.08-0.35$. These conditions are yet far from those required for engine certification, that is, low temperatures and pressures.

In the present paper, we will present the ignition of kerosene (JET A-1) droplets on a new, versatile set-up [21] with a plasma created via focused microwaves. We have already shown that this plasma is energetic enough to ignite ethanol droplets (with diameter $289 \mu \mathrm{m}$ ). As this set-up is a first step in the development of a new ignition device for air breathing engines for aircrafts and helicopters, using time reversed microwaves, the next logical step was to demonstrate the ignition of kerosene.

\section{Experimental Set-Up}

The experimental set-up has been described in detail in reference [21], see Figure 1. The main parts are briefly recalled in this paragraph. The set-up consists of the cavity with the initiators, the fuel injection system, the camera, the spectrometer and the microwaves system.

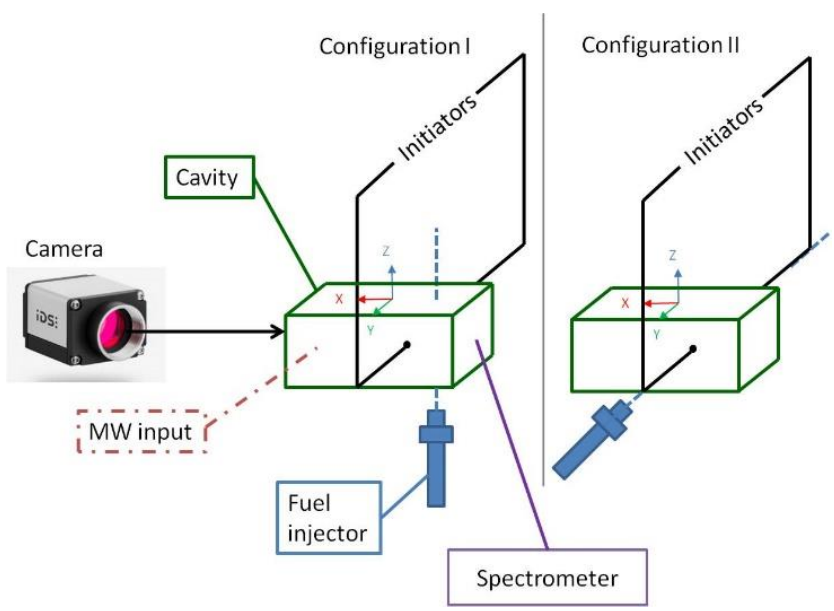

Figure 1. Schematic of the experimental set-up [21].

\section{Cavity}

The aluminium cavity used for the results presented below, is shown in Figure 2. We can see the position of the connector for the microwave input (feeding) and the initiators that create the gap zone. The cavity has been designed with several degrees of freedom to present a versatile set-up for a large variety of possible studies. It is designed for a resonance frequency of $f_{0}=2.45 \mathrm{GHz}$. As the resonance frequency is sensitive to changes in geometry, e.g. the use of different shapes of initiators, the length of the cavity can be adapted to keep the resonance frequency close to the targeted frequency. Additionally, a good matching between the coaxial connector and the cavity is needed in order to make sure that most of the energy delivered by the microwave generator enters the cavity. A good matching is defined from the value of the reflexion coefficient $S_{11}$, which is described in detail in the paragraph of the microwave system. To influence this parameter, we can change the penetration of the inner conductor of the coaxial connector and achieve a good matching for different configurations. In addition, we can change the direction of the fuel injection, as shown in Figure 1 configuration I and II. Further, the cavity is designed as a mono-modal cavity. Mono-modal means that at the resonance frequency only one mode exists in the cavity leading to a specific distribution of the 
electric and magnetic fields. In our cavity, we excite the transversal electric mode $\mathrm{TE}_{012}$, i.e. there is zero maximum of electric field along the z-axis, one maximum along the $y$-axis and two maxima along the $x$-axis (see the coordinate system shown in Figure 2). Near the first maximum in $x$-direction we place the connector and, at the second maximum, we place the initiators.

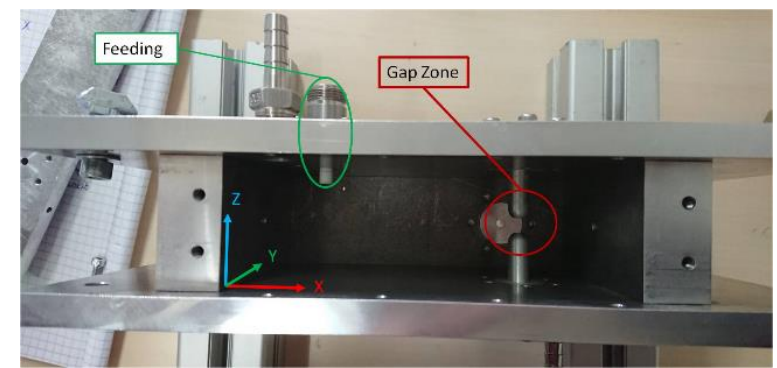

Figure 2. The cavity with one open side [21].

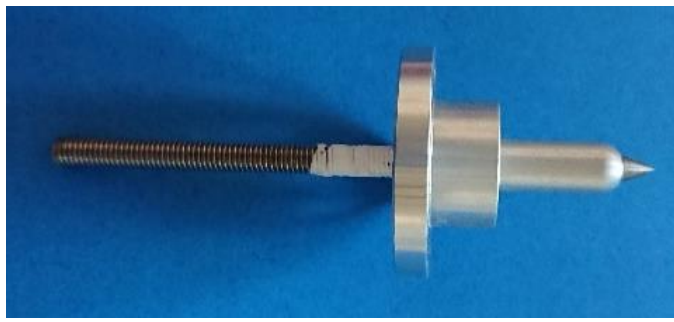

Figure 3. Stainless steel tip initiator.

\section{Initiators}

For the results presented in the article, we used stainless steel tips as initiators, see Figure 3. With these initiators only the configuration I in Figure 1 is possible. The advantage of this configuration is, that we can change the gap size between the initiators, which is fixed in configuration II. The role of the initiators is to focus the electric field between them. As they are already placed at the maximum of the electric field, this additional focusing leads to an increase in electric field density above the breakdown threshold of air and therefore the creation of a plasma in the gap zone. As can be seen in Figure 4, the tips are not symmetric. The geometry of the tips plays a role in the electric field enhancement. The sharper the edges the higher is the focused field and the more energy is at disposition for ignition. The initiators shown are sharp enough to ignite a plasma and it is more important not to change the shape during experiments than the initial geometric shape.

\section{Fuel Injector}

We used a monodisperse droplet generator (MDG) [22] for the fuel injection. It creates a monodisperse droplet stream using a piezoelectric ceramic, excited by a frequency generator. The droplet diameter $D_{d}$ can be written as [22]:

$$
D_{d}=\left(\frac{3 v D^{2}}{2 f_{\text {piezo }}}\right)^{\frac{1}{3}}
$$

With $D$ the pinhole diameter, $f_{\text {piezo }}$ the excitation frequency of the piezoelectric ceramic and $v$ the velocity of the droplet stream. In the experiments, the pinhole had a diameter of $D=50$ $\mu \mathrm{m}$ and the fuel velocity was $v=12.5 \mathrm{~m} / \mathrm{s}$. We used $f_{\text {piezo }}=21500 \mathrm{~Hz}$, which results in a droplet diameter of $D_{d}=130 \mu \mathrm{m}$. This value is calculated with an accuracy of $2 \%$ or better and has a standard deviation of $1 \%$ [22]. With these parameters we can calculate the distance between the droplets as well, which is around $0.58 \mathrm{~mm}$ for our droplet stream. The distance between droplets plays an important role, as for small distances, the ignition of a droplet influences the evaporation and the ignition of the following droplet. The larger the distance, i.e. the larger the ratio between distance and droplet diameter ( $\geq 10$ to 15), the more we approach the case of an isolated droplet. In our case this ratio is around 4.5. Therefore, the droplets influence each other and decrease the evaporation rate of the following droplets. 


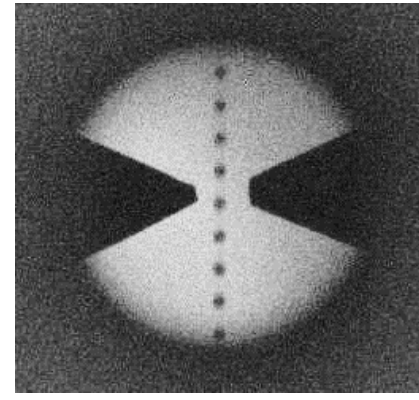

a

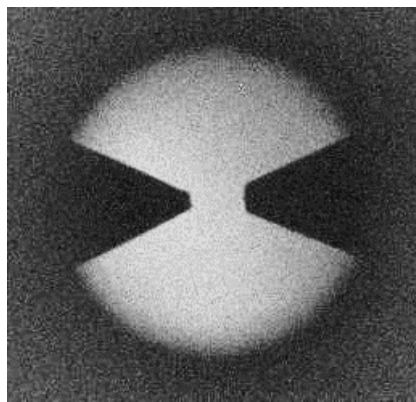

b

Figure 4. Visualisation of the gap zone during experiments: a) with the droplet stream, b) the gap alone and c)

with the plasma.

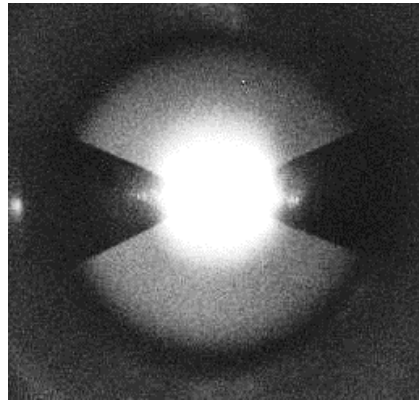

c

\section{Camera}

We used an IDS monochrome camera (model UI-5040SE Rev. 4) equipped with a $75 \mathrm{~mm}$ fixed focal length lens (DG series from Edmund Optics). At full resolution (1448 x 1086 pixels) the repetition rate is $73 \mathrm{fps}$. The camera was used for the visualisation of the droplet stream (shadowgraphy, Figure 4 a), the gap (Figure 4 b) and the plasma discharge between the initiators (Figure $4 \mathrm{c}$ ).

\section{Spectrometer}

We used the Avantes multichannel spectrometer to monitor successful ignition. During the combustion of hydrocarbons there are two molecules with strong chemiluminescence that can be detected by the spectroscope. First, the $\mathrm{CH}$ molecule that emits at a wavelength of $\lambda_{1}=$ $431 \mathrm{~nm}$ and secondly, the $\mathrm{C}_{2}$ molecule that emits at a wavelength of $\lambda_{2}=516 \mathrm{~nm}$. Figure 5 shows a typical emission spectra during a firing test. Flame occurrence is easily identified.

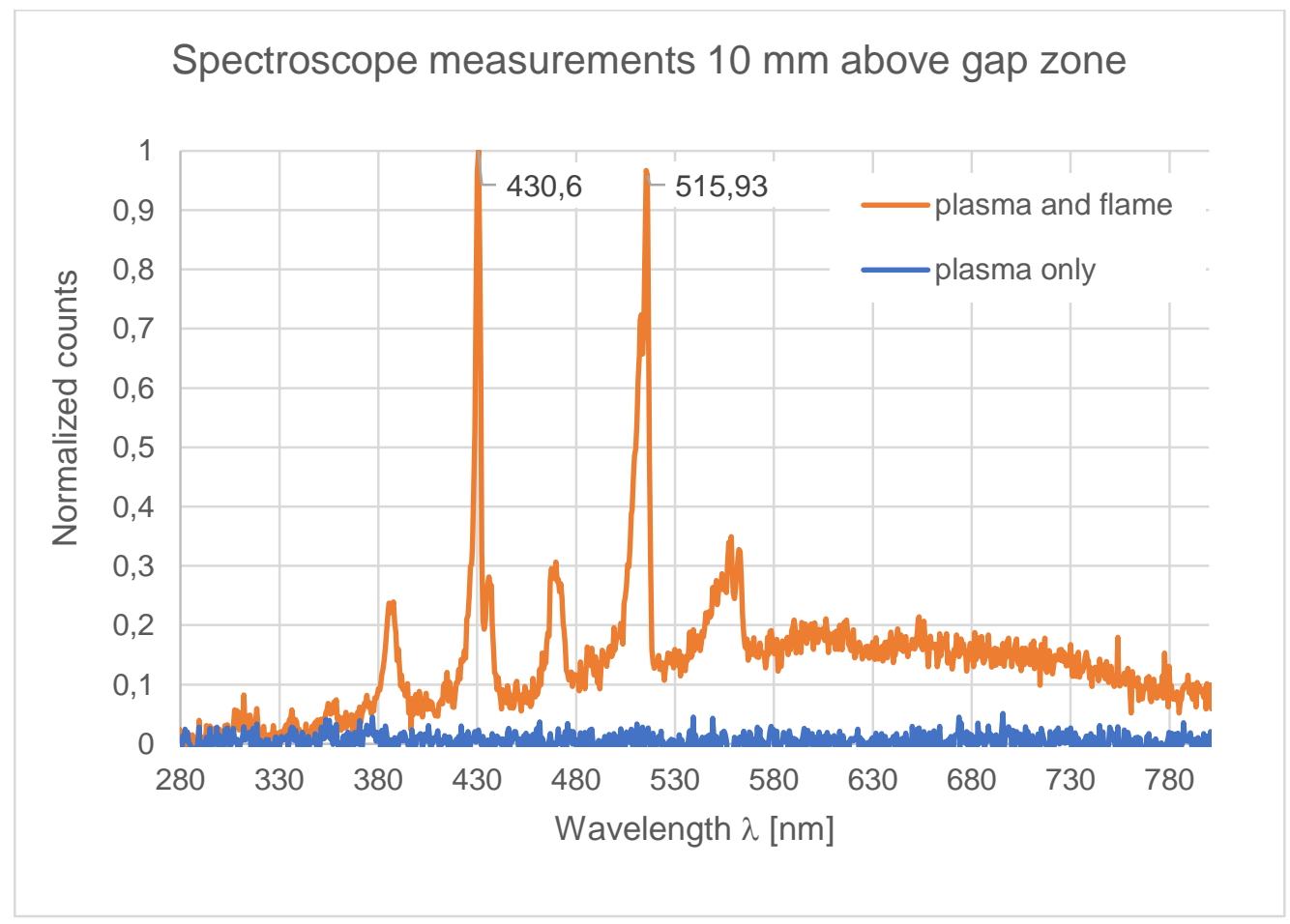

Figure 5. Example of spectroscope measurements. 


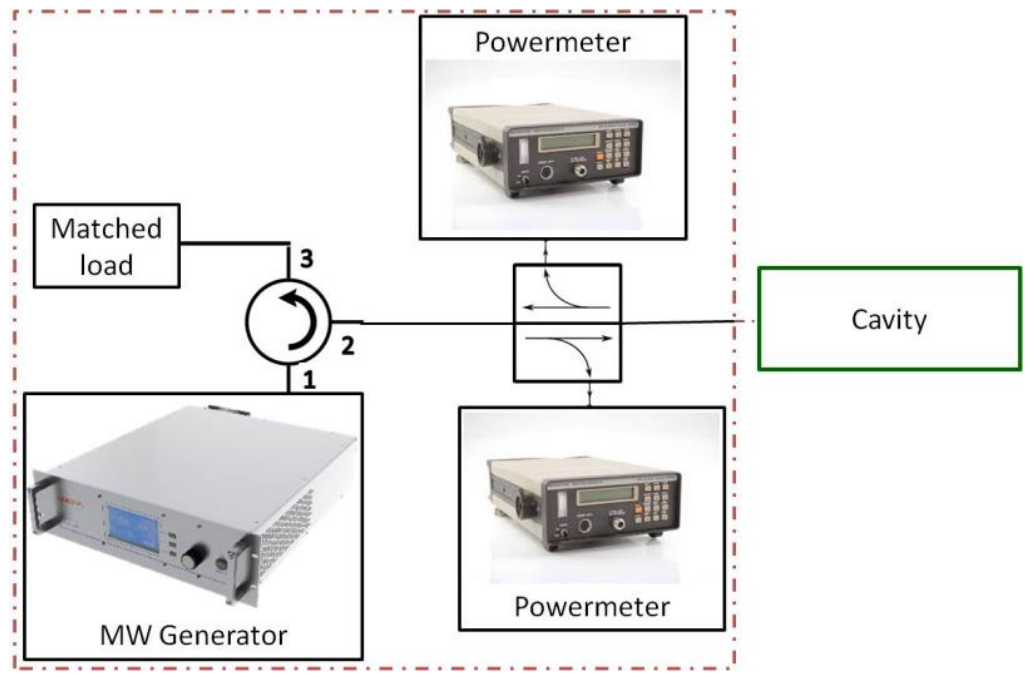

Figure 6. Schematic of the microwave system [21].

\section{Microwave system}

The Figure 6 shows the microwave system schematically. At the output of the Sairem solidstate microwave generator (Model GMS200W, f: $2.4 \mathrm{GHz}-2.5 \mathrm{GHz}, \Delta f: 100 \mathrm{kHz}$ ) we placed a circulator that redirects the reflected power into the matched load to protect the generator. Afterwards, we placed a coupler, that redirects a small part $(-30 \mathrm{~dB})$ from the incident power coming from the generator and the reflected power from the cavity to our Marconi power meters to measure these parameters. A code developed previously at the laboratory Laplace has been used to deduce the losses in the components and cables from these measurements in order to record the real power that is arriving and reflected at the cavity. An example of these measurements is shown in Figure 7.

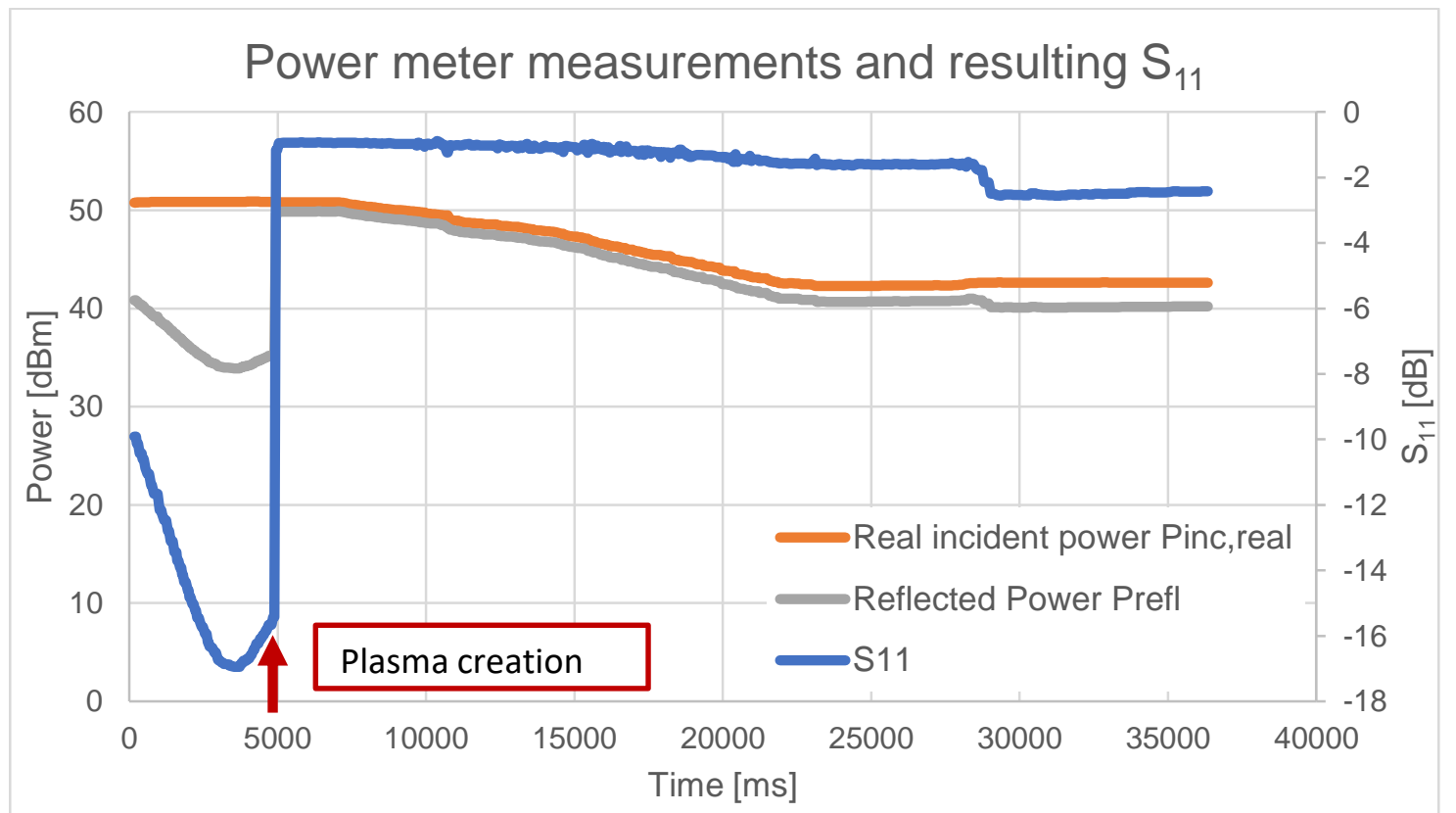

Figure 7. Power meter measurements of a typical experiment; The $S_{11}$ is measured on the right $y$-axis, the real incident and reflected power on the left y-axis.

In order to quantify the matching between the microwave input and the cavity, we use the reflection coefficient $S_{11}$, which is defined as follows: 


$$
S_{11}=10 \log \left(\frac{P_{\text {refl }}}{P_{\text {inc,real }}}\right)
$$

where we use the values for the reflected power $P_{\text {refl }}$ and the real incident power $P_{\text {inc, real }}$ that are measured with the power meters. In Figure 7, we can see the measurements of the power meters and the deduced $S_{11} . S_{11}$ with a value less than $-10 \mathrm{~dB}$ is called a good matching, as this value means that only $10 \%$ of the incident power arriving at the cavity entry is reflected and therefore, $90 \%$ of the power is effectively entering the cavity. The diagram shows that $\mathrm{S}_{11}$ is between -10 and $-17 \mathrm{~dB}$ at the beginning, and therefore most of the incident energy is entering the cavity. At one point $S_{11}$ suddenly jumps to a very high value of $\sim-2 \mathrm{~dB}$. That is the moment of plasma creation, which causes a huge degradation in terms of matching.

\section{Results and Discussion}

We conducted extensive experiments in order to determine the minimum power needed to ignite the kerosene droplet stream. First, we created a plasma between the initiators at 200 $\mathrm{W}$, before reducing the incident power to the desired value for the test. Even if the plasma can be created at lower incident powers than $200 \mathrm{~W}$ (see [21]), we decided to create the plasma at the maximum power to ensure a fast plasma creation for all gaps tested and to avoid heating of the cavity prior to the ignition test. After the incident power has been decreased to the targeted power level, we injected the droplet stream, created with the MDG. The power has been decreased first in steps of $10 \mathrm{~W}$ and then in steps of $1 \mathrm{~W}$ until we reached the power level where the droplets no longer ignite, which defines the last ignition power as the minimum. This protocol has been applied once for all gaps presented. With this approach we are able to ignite systematically until passing the minimum power. After each try, the cavity is purged with compressed air to evacuate remaining liquid fuel and vapours. The results of these tests for five different gap sizes are shown in Figure 8. The power entering the cavity $P_{\text {cav }}$ is calculated as follows from the power meter measurements:

$$
P_{\text {cav }}=P_{\text {inc,real }}-P_{\text {refl }}
$$

Decreasing the gap size yields a reduction of the minimum power needed for ignition. For the smallest gap tested (i.e. $0.8 \mathrm{~mm}$ ) a slight increase of $P_{\text {cav }}$ is observed, but this tendency has to be confirmed with more tests at even smaller gaps. We reach a minimum of $P_{\text {cav }}=4.5 \mathrm{~W}$ at a gap of $d_{g}=0.95 \mathrm{~mm}$. The presented power measurements have an uncertainty of $\pm 3.2 \%$, which are represented as error bars in Figure 8.

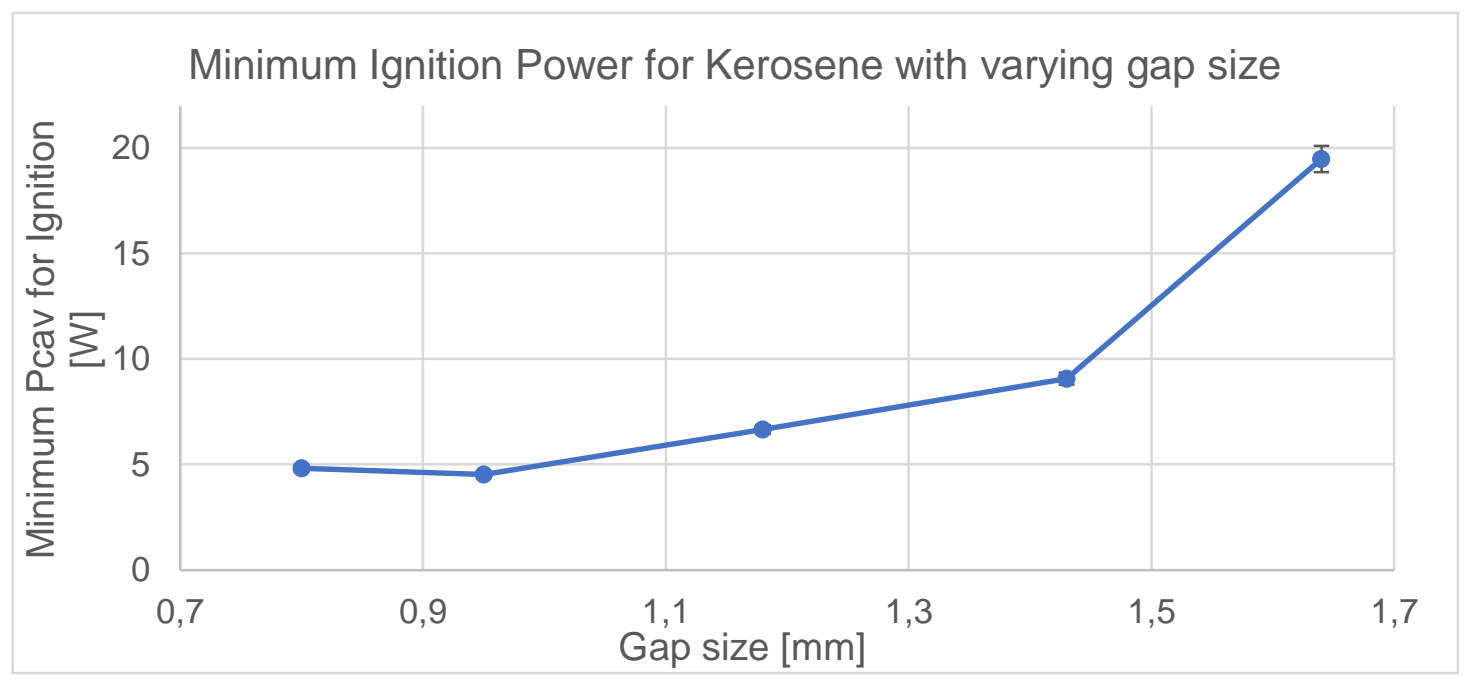

Figure 8. Results for the minimum ignition power of kerosene droplets (diameter $130 \mu \mathrm{m}$ ) for varying gaps. 
The presented results exhibit the same trend as those of Ballal et al. [23], that is the ignition energy decreases with the gap size down to an optimal value $d_{g}$. For a gap equal to $d_{g}$, the heat delivered in the ignition kernel just exceeds the heat losses to the surrounding medium. For gaps smaller than $d_{g}$, the needed energy for ignition increases again as the heat losses that are increasing as well have to be overcome for successful ignition. At larger gaps than $d_{g}$ the kernel volume increases and more energy is needed to heat up this volume to ignition temperature.

It would be interesting to compare our results to those of Ballal et al. in terms of minimum ignition energy. However, the set-up conditions differ widely and further work will be needed to provide a quantitative comparison.

\section{Conclusions}

We have shown in this paper that the plasma created via focused microwaves in our set-up is energetic enough to ignite a stream of kerosene droplets (diameter $D_{d}=130 \mu \mathrm{m}$ ). For a gap of $d_{g}=0.95 \mathrm{~mm}$, we only need $P_{c a v}=4.5 \mathrm{~W}$ entering the cavity for ignition. These results are very promising for our next challenge: the application of time reversal [24] to ignite a spray. The present study gives us an idea of the power needed for kerosene ignition and therefore the power we need to focus via time reversal to apply this principle in a new ignition device. Finally, it would be interesting to find a method to determine the energy transferred to the droplets in our set-up and to compare to the results in the literature.

\section{Acknowledgements}

We like to thank the RTRA STAE Toulouse (Réseau thématique de recherché avancée Sciences et Technologies pour l'Aéronautique et l'Espace) for financial support as well as Geoffroy Illac for his technical support to this work. Without this support, this study would not have been possible.

\section{Nomenclature}

$\begin{array}{ll}E_{\text {min }} & \text { Minimum ignition energy } \\ D & \text { Pinhole diameter }[\mathrm{m}] \\ D_{d} & \text { Droplet diameter }[\mathrm{m}] \\ d_{g} & \text { Optimal Gap size }[\mathrm{m}] \\ \Delta f & \text { Frequency step }[\mathrm{Hz}] \\ f & \text { Frequency }[\mathrm{Hz}] \\ f_{0} & \text { Resonance frequency }[\mathrm{Hz}] \\ f_{\text {piezo }} & \text { Excitation frequency of the piezoelectric ceramic }[\mathrm{Hz}] \\ M_{\text {air }} & \text { Mach number of air flow } \\ P_{\text {air }} & \text { Air pressure } \\ P_{\text {inc, real }} & \text { Real incident power arriving at the cavity } \\ P_{\text {refl }} & \text { Reflected power from the cavity } \\ T_{\text {fuel }} & \text { Fuel temperature } \\ T_{\text {air }} & \text { Air temperature } \\ S_{11} & \text { Reflection coefficient } \\ v & \text { Fuel velocity }\end{array}$

\section{References}

1. MA, J. X., ALEXANDER, D. R., POULAIN, Dana E. Laser spark ignition and combustion characteristics of methane-air mixtures. Combustion and Flame, 1998, vol. 112, no 4, p. 492-506.

2. KROUPA, G., BOERNER, M. A miniaturized high energy laser for ignition of rocket engines. In : International Conference on Space Optics - ICSO 2018. International Society for Optics and Photonics, 2019. p. 1118051. 
3. DISCEPOl, G., CRUCCOlINI, V., RICCI, F., DI GIUSEPPE, A., PAPI, S., GRIMALDI, C. N. (2020). Experimental characterisation of the thermal energy released by a Radio-Frequency Corona Igniter in nitrogen and air. Applied Energy, 263, 114617.

4. AUZAS, Frédéric. Décharge radiofréquence produite dans les gaz à pression élevée pour le déclenchement de combustion. 2008. Thèse de doctorat. Paris 11.

5. BURSTOW, D. J., LOVELAND, R. J., TOMLINSON, R., WIDGINTON, D. W. (1981). Radio frequency ignition hazards. Radio and Electronic Engineer, 51(4), 151-169.

6. KOGELSCHATZ, U., ELIASSON, B., EGLI, W. Dielectric-barrier discharges. Principle and applications. Le Journal de Physique IV, 1997, vol. 7, no C4, p. C4-47-C4-66.

7. DENG, J., PENG, C., HE, L., WANG, S., YU, J., ZHAO, B. (2019). Effects of Dielectric Barrier Discharge Plasma on the Combustion Performances of Reverse-Flow Combustor in an Aero-Engine. Journal of Thermal Science, 28(5), 1035-1041.

8. LOVASCIO, S., HAYASHI, J., STEPANYAN, S., STANCU, G. D., LAUX, C. O. (2019). Cumulative effect of successive nanosecond repetitively pulsed discharges on the ignition of lean mixtures. Proceedings of the Combustion institute, 37(4), 5553-5560.

9. PANCHESHNYI, S. V., LACOSTE, D. A., BOURDON, A., LAUX, C. O. (2006). Ignition of propane-air mixtures by a repetitively pulsed nanosecond discharge. IEEE Transactions on Plasma Science, 34(6), 2478-2487.

10. DAVYDOV, A. M., GRITSININ, S. I., KOSSYI, I. A., SHIKHMAN, Y. M., VINOGRADOV, V. A. (2008). Application of MW plasma generator for ignition of kerosene/air mixture. IEEE Transactions on Plasma Science, 36(6), 29092917.

11. GHOBRIAL, S. I., VERMA, M. K., HOWSON, D. P. Hazards to inflammable fuels and vapours due to induced microwave radiation. Radio and Electronic Engineer, 1976, vol. 46, no 2, p. 64-68.

12. EXCELL, P. S. Ignition of flammable gas mixtures by X-band microwave discharges. IEE Proceedings $A$ (Physical Science, Measurement and Instrumentation, Management and Education, Reviews), 1984, vol. 131, no 2, p. $103-$ 110.

13. LINKENHEIL, K., RUOß, H. O., GRAU, T., SEIDEL, J., HEINRICH, W. (2005). A novel spark-plug for improved ignition in engines with gasoline direct injection (GDI). IEEE transactions on plasma science, 33(5), 1696-1702.

14. WILHELM, J., PERTL, F., WILLDFIRE, P., SMITH, J. (2008). Ignition energy testing of the quarter wave coaxial cavity resonator with air-liquefied-petroleum-gas mixtures. In 39th Plasmadynamics and Lasers Conference ( $p$. 3775).

15. PERTL, F. A., SMITH, J. E. Electromagnetic design of a novel microwave internal combustion engine ignition source, the quarter wave coaxial cavity igniter. Proceedings of the Institution of Mechanical Engineers, Part D: Journal of Automobile Engineering, 2009, vol. 223, no 11, p. 1405-1417.

16. PERTL, F. A., CLARKE, M. A., SMITH, J. E. Design of a compact quarter wave coaxial cavity resonator for plasma ignition applications. International Journal of Microwave and Wireless Technologies, 2011, vol. 3, no 4, p. 485.

17. STEVENS, C. A., PERTL, F. A., HOKE, J. L., SCHAUER, F. R., SMITH, J. E. (2011). Comparative testing of a novel microwave ignition source, the quarter wave coaxial cavity igniter. Proceedings of the Institution of Mechanical Engineers, Part D: Journal of Automobile Engineering, 225(12), 1633-1640.

18. WANG, Z., WANG, Y., ZHU, L., MA, W., SHAN, J., LIU, F. (2019). Experimental study of influence on microwave plasma ignition combustion performance of pulse microwave signals. IEEE Access, 7, 23951-23958.

19. STARIKOVSKAIA, Svetlana M. Plasma assisted ignition and combustion. Journal of Physics D: Applied Physics, 2006, vol. 39, no 16, p. R265.

20. STARIKOVSKIY, A., ALEKSANDROV, N., Plasma-assisted ignition and combustion. Progress in Energy and Combustion Science, 2013, vol. 39, no 1, p. 61-110.

21. FRAGGE, B., SOKOLOFF, J., ROUZAUD, O., PASCAL, O., ORAIN, M., A versatile set-up to study plasma/microwave sources for liquid fuel ignition, Eur. Phys. J. Appl. Phys. 92, 30903 (2020)

22. BERGLUND, R. N., LIU, B. YH. Generation of monodisperse aerosol standards. Environmental Science \& Technology, 1973, vol. 7, no 2, p. 147-153.

23. BALLAL, D. R., LEFEBVRE, A. H. Ignition and flame quenching of flowing heterogeneous fuel-air mixtures. Combustion and Flame, 1979, vol. 35, p. 155-168.

24. FINK, Mathias. Time-reversed acoustics. Scientific American, 1999, vol. 281, no 5, p. 91-97. 